\title{
As redes de apoio social das mulheres ribeirinhas da Amazônia: Uma abordagem ecológica
}

\author{
Neuqeli Maria de Almeida Pinto* \\ Fernando Augusto Ramos Pontes** \\ Simone Soura da Costa Silva***
}

\begin{abstract}
Resumo
O objetivo deste estudo foi analisar a percepção sobre as redes de apoio a partir da sistematização das experiências das mulheres ribeirinhas moradoras em Ilhas de Belém-PA. Para essa análise foram utilizados o mapa dos cinco campos (MCC), o inventário sócio demográfico (ISD) e uma entrevista semiestruturada. Constatou-se uma intensa rede de apoio social mantida pelas mulheres em todos os campos estudados e a existência de uma rede que permite às mulheres a circulação em vários contextos e a interação entre as pessoas de outros microssistemas de modo adaptado. Constatou-se uma intensa rede de apoio social mantida pelas mulheres em todos os campos estudados, a existência de uma rede que thes permite a circulação em vários contextos e a interação entre as pessoas de outros microssistemas de modo adaptado. Essas experiências criam condições para a presença feminina nos movimentos sociais. Apesar de a comunidade se beneficiar de projetos de desenvolvimento comunitário, tais famílias ainda permanecem em um contexto de vulnerabilidade social. Concluiu-se que este trabalho pode ser útil para a compreensão dos efeitos de políticas públicas e proposta de ações comunitárias com bases democráticas e sustentáveis)
\end{abstract}

Palavras-chave: Mulheres, Rede de apoio social, Ribeirinhas, Amazônica, Trabalho, Açaí.

\section{The social support networks of women riverine Amazon: An ecological approach}

\begin{abstract}
The objective of this study was to analyze the perception of the support networks based on the systematization of the experiences of the riverside women living in islands of Belém-PA. For this analysis, the five-field map (MCC), the socio-demographic inventory (ISD) and a semi-structured interview were used. There was an intense social support network maintained by women in all the fields studied, the existence of a network that allows them to circulate in various contexts and the interaction among people from other microsystems in an adapted way. These experiences create new conditions for the female presence in social movements. Although the community benefits from community development projects, such families still remain in a context of social vulnerability. It is concluded that this work may be useful for understanding the effects of public policies and for proposals with democratic and sustainable bases of community actions.
\end{abstract}

Keywords: Women, social support network, Riparian, Amazon, Work, Açaí.

\footnotetext{
* Doutora em Teoria e Pesquisa do Comportamento na UFPA/PA, Mestre em Psicologia pela USP/SP, Graduada em Economia Doméstica pela UFV e Professora da Universidade Estadual do Maranhão - UEMA.

** Doutor em Psicologia Experimental da USP/SP, Mestre, Psicólogo e Professor associado - Universidade Federal do Pará.

***Pós-Doutorado pela Universidade de Dortmund - Alemanha, Doutorado pela Universidade de Brasília, Psicóloga e Mestre pela UFPA/PA e Professora e Diretora Adjunta do Núcleo de Teoria e Pesquisa do Comportamento do curso de graduação em Psicologia da UFPA/PA.
} 


\section{Introdução}

A modernização da sociedade brasileira trouxe uma série de transformações na atuação da mulher nos vários contextos, que afetaram diferencialmente as classes ou camadas sociais. Dentre essas mudanças, destaca-se a entrada de mulheres e filhos no mercado de trabalho, seja no setor formal ou informal, como meio de aumentar a renda familiar em face das necessidades de consumo (Simões \& Hashimoto, 2012). Como consequência do aumento da participação feminina em atividades profissionais remuneradas houve alteração na posição das mulheres na estrutura da família, no trabalho e na comunidade.

No contexto das camadas populares, frequentemente, a contribuição da mulher para suprir as necessidades da família ocorre tanto por meio do trabalho doméstico, produtor de valores de uso, como pela atividade profissional remunerada, no mercado formal ou informal de trabalho. No entanto, em função da baixa qualificação da força de trabalho das mulheres das classes populares e da desvalorização geral do trabalho feminino, a remuneração que elas podem obter é, de modo geral, pequena. Além disso, o trabalho remunerado, muitas vezes, é realizado simultaneamente com as tarefas domésticas, acarretando, assim, uma dupla jornada de trabalho (Ávila, 2007).

Há, portanto, necessidade de soluções conciliatórias entre o trabalho da mulher e a vida familiar, tanto no âmbito das práticas quanto das representações. Ou seja, diferentes arranjos familiares estão sendo construídos a partir da constituição de redes sociais familiares e não familiares para dar novos significados sobre família, mulher e homem. Estes novos modelos familiares estão sendo produzidos em intersecção com os modelos tradicionais por meio de negociações na convivência diária (Montali, 2014).

Tais soluções conciliatórias são fatores importantes para as mulheres terem condições de desenvolverem a dupla jornada de trabalho. $\mathrm{Na}$ maioria das vezes há uma integração com redes de apoio social mais ampla de ajuda mútua, que envolvem parentes e vizinhos. Assim, as redes de apoio contribuem para satisfazer as necessidades dos membros da família. A integração das famílias de classes populares nas "redes horizontais" de troca de favores e solidariedade tem a função de assegurar socialmente e financeiramente essas famílias. A importância dessas redes cresce à medida que as famílias criam vínculos de dependência mútua (Machado, 2014).

As redes de apoio social mantidas pelas mulheres garantem a participação delas como mediadora central em todas as atividades desenvolvidas na família e comunidade. Dos mais variados arranjos desenvolvidos pelas famílias de baixa renda, a coleta do açaí apresenta um arranjo peculiar. Em razão de as mulheres estarem diretamente e intensivamente envolvidas, e as atividades serem desenvolvidas em comunidades ribeirinhas e nos arredores do domicílio familiar, há uma conjugação extremamente próxima da atividade de ocupação e renda com a rotina doméstica. A coleta do açaí interfere na vida dessas famílias no desenvolvimento da atividade produtiva tanto dentro da família como na comunidade (Pinto, Pontes \& Silva, 2013).

A compreensão dessas questões pode ser feita por meio do conceito de microssistema de Bronfenbrenner (1996, p.18) como "padrão de atividades, papéis e relações interpessoais experenciados pela pessoa em desenvolvimento em um dado ambiente com características físicas e materiais específicas".

Nessa perspectiva, a definição de rede de apoio pode ser analisada como sendo uma articulação entre os três núcleos do modelo (processo, contexto e tempo), os quais estarão tingidos pelas características pessoais dos membros familiares e grupos participantes.

Além disso, as redes de apoio social não se limitam apenas a um ambiente único e imediato, e deve ser "concebido topologicamente como uma organização de estruturas concêntricas, cada uma contida na seguinte" (Bronfenbrenner, 1996, p.18), formando por sua vez várias dimensões do contexto (micro, meso, exo e macrossistema). Assim, os contextos interferem mutuamente, que implica um processo de construção permanente tanto em nível individual quanto coletivo.

O apoio social é definido como um processo no qual a pessoa maneja seus recursos para atender as suas necessidades. Nas redes de apoio destacam-se, os suportes comportamentais - enquanto atos específicos de ajuda que ocorrem durante um relacionamento -, e a percepção de suporte, traduzidas como uma estimativa pessoal e subjetiva dos próprios recursos e do que foi oferecido pela rede de apoio disponível. (Vaux, 1988)

O apoio social é visto como importante dimensão do desenvolvimento, uma vez que constitui a ponte de interrelação entre a pessoa e o sistema social no qual está inserida. $\mathrm{O}$ apoio afetivo é uma variável que mantêm os vínculos e marca a qualidade da relação (Bronfenbrenner, 1996). Os apoios social e afetivo estão relacionados à percepção que a pessoa tem de seu mundo social, de suas formas de estabelecer e manter vínculos, das fontes que lhe ofertam recursos de proteção e força (Vaux, 1988), bem como promovem reconhecimento, sentimento de identidade, de competência e de ação. 
O Brasil é um país com grande variedade populacional, com culturas, histórias e situações socioeconômicas diferenciadas, contextos estes multifacetados, sem dúvida, imprimem peculiaridades nas redes de apoio social. A Amazônia brasileira por sua história social e cultural e por seus ecossistemas é um desses contextos onde as populações possivelmente vivenciam experiências particulares. Nesse espaço, o ribeirinho é descrito pelos pesquisadores como um personagem central no processo histórico e social da região (Cruz, 2008).

\section{O contexto ribeirinho amazônico}

Nos últimos anos, a região Norte do Brasil, que faz parte da denominada Amazônia legal, sofreu uma grande explosão populacional. Esse crescimento foi acompanhado pelo desenvolvimento de alguns polos industriais e consequente impulsão da economia. Contudo, tais mudanças contrastam com uma realidade indigna, quando não assustadora, vivida pelos trabalhadores ribeirinhos.

Apesar da grande diversidade ecológica da floresta amazônica, seu solo é pobre em nutrientes, dificultando assim, o desenvolvimento de agricultura sustentável de produtos que poderiam ser consumidos e comercializados pelas famílias ribeirinhas. Esse fator pode levar à intensificação dos processos de ocupação humana e de exploração de seus recursos naturais de forma desordenada. Aliado a isto, os costumes e valores culturais das famílias ribeirinhas funcionam como mediadores no processo de ocupação e utilização dos recursos naturais da floresta amazônica. Assim, as representações em relação à Amazônia, a sua preservação ou exploração se relacionam de forma concomitante, construindo e se dinamizando no decorrer do desenvolvimento histórico dessas famílias. (Simonian, 2007)

Os ribeirinhos dependem da "terra do trabalho" para a prática de agricultura, mas também precisam de acesso às "águas do trabalho", na qual desenvolvem atividades de pesca. Com isso os ribeirinhos são muitas vezes levados a plantar mais e, na época apropriada, extrair mais recursos da floresta como no caso das frutas. Nesse sentido, embora o trabalho esteja essencialmente voltado à produção familiar, a comercialização do excedente ocorre com frequência nos grandes centros em períodos de maior demanda (Lomba \& Nobre-Junior, 2013).

Nesta perspectiva, a distância em relação aos centros urbanos constitui um aspecto que precisa ser considerado, pois dela depende não somente a comercialização de produtos, mas também o acesso a elementos com características relevantes de culturas urbanizadas. Assim, quanto menos distante dos centros urbanos, mais as comunidades ribeirinhas têm acesso a serviços e produtos referentes à educação, saúde, trabalho, etc. Atualmente verifica-se que os ribeirinhos praticam uma gama de atividades econômicas, moram em ambientes rurais e urbanos, desempenhando um importante papel no desenvolvimento da região. Neste sentido, entende-se que apesar de se tratar de um cotidiano que reproduz ações, ditas tradicionais, os ribeirinhos estão inseridos em um processo de transformação no seu modo de viver. Suas manifestações culturais e sociais se expandem pelo mundo urbano e vice-versa, assimilando algumas práticas e rejeitando outras (Carneiro, Fraxe, Mourão \& Rivas, 2007).

Dentre as várias práticas e ligações existentes entre os ribeirinhos, no cotidiano dos centros urbanos se destaca a coleta extrativista do açaí realizada nas comunidades ribeirinhas amazônicas e a sua comercialização nos centros urbanos. O cultivo do açaí é realizado, na sua maior parte, por essas comunidades localizadas às margens de pequenos rios, conhecidos por Furos, rios estreitos, cercado de vegetação, que funcionam como se fossem ruas. O ribeirinho vive da caça, da pesca, do extrativismo de produtos florestais, dentre eles a coleta do açaí. No entanto, dentre todas as atividades, a coleta do açaí é a principal geradora de renda para a maioria das famílias durante a safra, que acontece de agosto a dezembro, período que ocorre também uma maior movimentação financeira. Na época da entressafra, as comunidades passam por dificuldades financeiras com a baixa produção, pois é na época do inverno que acontecem as grandes cheias dos rios, inviabilizando atividades como a pesca e a produção agrícola sustentável.

A partir do contexto social ribeirinho, interrogam-se como mulheres, trabalhadoras na coleta do açaí percebem suas redes de apoio social e afetivo. Sendo, portanto, relevante identificar como se estrutura e funciona a rede de apoio social nesse contexto sócio ecológico, para que se viabilizem estratégias de suporte a estas mulheres.

\section{Método}

\section{Participantes}

Participaram da pesquisa 12 mulheres agroextrativistas, sendo seis delas da Ilha Grande/Comunidade São José e 06 da Ilha Combu/Comunidade Santo Antônio, na região da Belém Insular - PA. As participantes desempenhavam atividades da coleta do açaí e estavam envolvidas em movimentos da associação comunitária das ilhas. Os filhos que não moravam com a família, estavam na mesma 
comunidade ou no mesmo terreno e alguns moravam em Belém-PA. A família extensa constituída com agregados é uma característica das famílias das comunidades.

\section{Ambiente de coleta}

A coleta dos dados foi realizada nas casas das mulheres ribeirinhas. As ilhas são administrativamente subordinadas à capital e estão a cerca de $12 \mathrm{~km}$ de distância de Belém, cujo transporte só é realizado via fluvial, pelo rio Guamá, que separa a ilha da parte continental do Estado. O cotidiano local é marcado por um ir e vir constante entre o mundo insular e o continente. A travessia à capital é necessária para vender os recursos extraídos, efetuar compras, frequentar aulas ou realizar pequenos serviços, o que concorre para a construção de um modo de vida bastante peculiar. A comunidade vivencia uma realidade sociocultural marcada pelo contraste entre as riquezas naturais e a situação de pobreza social em que se encontra a maioria da população local (Pinto, Afonso, Pontes \& Silva, 2016).

A população das duas comunidades que fazem parte desta pesquisa tem como principal atividade de sobrevivência o extrativismo, destacando-se a coleta de açaí, além de outras frutas como cacau e cupuaçu, em menor escala, sendo esses produtos destinados ao consumo e à comercialização em Belém. Apesar das dificuldades, a proximidade com Belém supre algumas necessidades locais, principalmente no que diz respeito à educação e à saúde.

\section{Instrumentos}

A coleta de dados foi realizada por meio da aplicação de uma entrevista semiestruturada, do Mapa dos Cinco Campos (M5C) e diário de campo (DC). A entrevista semiestruturada consistiu na identificação, por meio dos dados pessoais, da rede de parentesco no local, do perfil familiar, das condições de vida, concepções pessoais sobre papéis no trabalho, na comunidade e na família, relação de apoio e conflito com a família, com os parentes, vizinhos e amigos, grupo de trabalho da coleta do açaí e Associação comunitária.

O M5C foi utilizado com o objetivo de identificar a estrutura (quantidade dos vínculos estabelecidos na rede) e a função (qualidade dos vínculos) da rede de apoio das mulheres na execução das atividades ligado aos contextos em que participam (Samuelsson, Thernlund \& Ringstrom, 1996, adaptado por Hoppe, 1998).

O M5C consistiu em um quadro de banner com medidas de $60 \times 90 \mathrm{~cm}$. Nesse quadro, estão desenhados seis círculos concêntricos verdes, que vão perdendo a intensidade da cor à medida que os círculos vão se distanciando do centro, caracterizando o enfraquecimento das relações. E finalmente o círculo vermelho que caracteriza os conflitos existentes nas relações.

Figura 1. Desenho do M5C tal como apresentado no banner para os participantes.

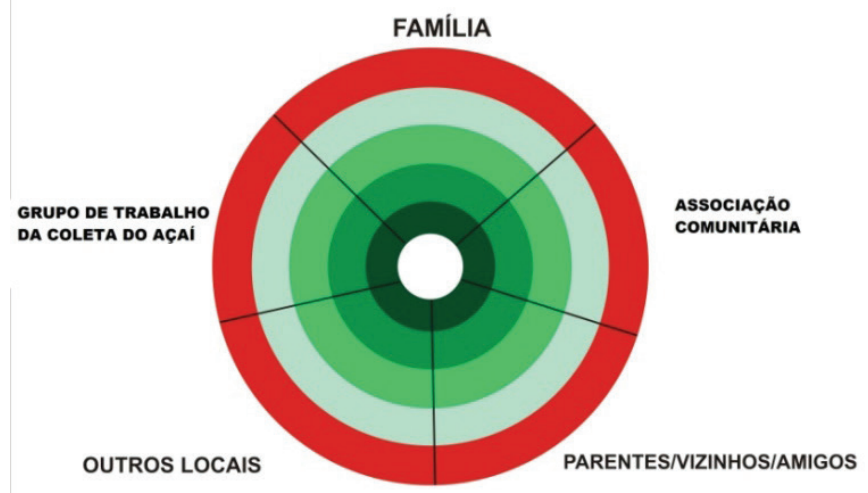

\section{Procedimentos da coleta e análise}

A pesquisa foi submetida e aprovada no Comitê de Ética do Instituto de Ciências da Saúde da Universidade Federal do Pará CEP-ICS/UFPA, parecer no 130/10. Para todas as participantes envolvidas na pesquisa foi solicitada a assinatura do "Termo de Comprometimento" e do "Termo de Livre Consentimento e Esclarecido", mediante informações prévias a respeito do conteúdo do mesmo.

A escolha das participantes foi efetuada considerando aspectos de acessibilidade, disponibilidade, além da participação das mulheres nas redes de apoio no exercício das atividades domésticas, de sua atuação na coleta do açaí e em movimentos sociais da comunidade.

$\mathrm{Na}$ sequência, foi feita a habituação e aplicação dos instrumentos de coleta de dados na casa das participantes. O primeiro a ser aplicado foi o Inventário Sociodemográfico. Posteriormente, foi realizada a aplicação da entrevista semiestruturada e do M5C. As questões foram lidas pela pesquisadora e as respostas assim como os comentários das participantes foram gravadas para transcrição posterior. Os conteúdos foram analisados seguindo os temas definidos a priori, no entanto, relatos espontâneos das mulheres foram registrados e analisados. Os instrumentos foram aplicados individualmente, em uma única sessão, com uma duração média de 50 minutos.

Os dados da entrevista semiestruturada foram analisados qualitativamente. Tal procedimento objetivou relacionar aspectos socioeconômicos das famílias com a sua rede de parentesco no local e a percepção das respondentes sobre sua rede de apoio. Os dados do DC foram analisados a partir da sistematização das experiências das 
participantes a fim de verificar a percepção sobre a rede de apoio, seu trabalho na coleta do açaí e atuação na associação comunitária e a divisão de tarefas na família. A análise do M5C segue os procedimentos descritos por Siqueira, Betts \& Dell'Aglio (2006). A estrutura das redes foi avaliada por meio de (1) número total de pessoas por nível de proximidade; (2) por campo; e (3) em toda a rede. A qualidade dos vínculos (função) foi avaliada a partir da (1) colocação das pessoas nos círculos adjacentes ao centro, que representam os níveis de proximidade: o primeiro e o segundo níveis correspondem às relações mais próximas; o terceiro e o quarto níveis correspondem às relações mais distantes; e o último nível (periférico, em vermelho) representa os contatos insatisfatórios e com rompimento; (2) média das relações caracterizadas por conflitos e rompimentos; (3) qualidade da relação; e (4) fator de proximidade por campo e total.

O fator de proximidade é uma variável que representa o grau de vinculação das participantes com o número de pessoas citadas nos campos, sendo medido por meio da localização dessas pessoas em relação ao círculo central, no qual está a participante. Para o cálculo desse escore, o número de pessoas colocadas no primeiro círculo é multiplicado por oito, no segundo nível por quatro, no terceiro nível por dois, no quarto nível por um, e no quinto nível por zero. O somatório desse cálculo é dividido pelo número total de pessoas citadas no campo, para a média de proximidade no campo, ou pelo número total de pessoas citadas no $\mathrm{M} 5 \mathrm{C}$, ou ainda para a média de proximidade do mapa (Samuelsson, Thernlund \& Ringstrom, 1996, adaptado por Hoppe, 1998).

\section{Resultados}

\section{Caracterização geral dos participantes.}

A aplicação do ISD permitiu identificar que todas as mulheres que participaram da pesquisa eram casadas, em união estável; sendo somente duas recasadas e tinham filhos da união anterior. Apenas 04 mulheres faziam parte de famílias nucleares, e 08 famílias caracterizavam-se como extensas: compostas por netos, sobrinhos e genros que habitavam junto ao núcleo familiar. Observa-se, ainda, que a maioria dos moradores tem algum grau de parentesco. A comunidade São José/Ilha Grande é composta por uma única rede de parentesco, com famílias compondo uma rede multigeracional, incluindo avós, pais, tios primos, filhos e netos de uma mesma rede familiar.

\section{Estrutura da rede de apoio de mulheres ribeirinhas}

A estrutura das redes foi avaliada por meio de (1) número total de pessoas por nível de proximidade; (2) por campo; e (3) em toda a rede. $\mathrm{Na}$ análise por níveis de proximidade, foi encontrada a média maior $(24,66)$ de contatos no primeiro nível em relação aos contatos do segundo $(12,83)$; contatos no terceiro nível (4) e os contatos do quarto nível $(1,5)$ e em outros locais $(0,75)$. Apesar de o campo Grupo de Parentes/Vizinhos/ Amigos apresentar um maior número de contatos $(22,08)$, comumente, os dados mostram também que esse campo apresenta um menor nível de proximidade (Tabela 1).

Tabela 1. Frequência total de contatos por Campo e por Nível de Proximidade.

\begin{tabular}{lccccc}
\hline Campos & \multicolumn{5}{c}{ Nível } \\
\cline { 2 - 6 } & $\boldsymbol{F}$ & $\mathbf{M}$ & & $\boldsymbol{F}$ & $\mathbf{M}$ \\
\hline Família & 65 & 5,41 & $\mathbf{1}^{\mathbf{0}}$ & 296 & 24,66 \\
Parentes/ Vizinhos/ Amigos & 265 & 22,08 & $\mathbf{2}^{\mathbf{0}}$ & 154 & 12,83 \\
Grupo de trabalho Coleta do Açaí & 52 & 4,33 & $\mathbf{3}^{\mathbf{0}}$ & 48 & 4 \\
Associação Comunitária & 87 & 7,25 & $\mathbf{4}^{\mathbf{0}}$ & 18 & 1,5 \\
Outros locais & 80 & 6,66 & $\mathbf{5}^{\mathbf{0}}$ & 9 & 0,75 \\
Mapa & 549 & 45,75 & & & \\
\hline
\end{tabular}




\section{Função da rede de apoio de mulheres ribeirinhas.}

O M5C permitiu identificar o número de contatos satisfatórios, insatisfatórios, conflitos e rompimentos e o grau de proximidade. As participantes investigadas mencionaram 549 pessoas, sendo estabelecido o maior número de contatos no campo dos parentes/vizinhos/ amigos, mencionando 265 pessoas, enquanto o campo do grupo da coleta do açaí apresentou o menor número, com 52 pessoas mencionados.

Os 71 filhos e 12 maridos das famílias estudadas foram citados repetidas vezes no campo da Família, no Grupo da coleta do Açaí, no Grupo de Parentes/ Vizinhos/Amigos e na Associação comunitária. Assim, foram levantadas a frequência e a localização dos maridos e filhos no M5C. De acordo com a Tabela 4, os maridos e filhos foram citados no nível mais próximo ao centro repetidas vezes em vários campos. Além disso, vale destacar que apenas uma participante citou o marido no quarto nível e nenhuma citou o marido ou os filhos no quinto nível. Entretanto, mais da metade dos filhos foram citados no primeiro nível (66,3\%), e no segundo nível essa percentagem é menor $(24,2 \%)$, seguindo no terceiro nível $(9,4 \%)$, no quarto e quinto nível não foram citados nenhum filho. Na tabela 2, apresentam-se também os campos onde os maridos e filhos são citados repetidas vezes. Observa-se que todos os maridos e filhos são citados no campo da Família e todos os maridos são citados também no campo do Grupo de Trabalho da Coleta do Açaí e menos da metade dos filhos são citados neste mesmo campo $(24,2 \%)$ e no campo da Associação Comunitária apenas um marido é citado $(8,3 \%)$.

Tabela 2. Frequência e Percentuais da Citação de marido e filhos por níveis de Proximidade nos diferentes campos do Mapa.

\begin{tabular}{|c|c|c|c|c|c|c|c|c|c|}
\hline \multirow[t]{2}{*}{ Campos } & $\begin{array}{l}\text { Marido } \\
(\mathrm{n}=12)\end{array}$ & \multicolumn{3}{|c|}{$\begin{array}{l}\text { Filhos } \\
(n=71)\end{array}$} & \multirow[t]{2}{*}{ Nível } & \multirow{2}{*}{$\begin{array}{c}\begin{array}{r}\text { Marido } \\
(\mathrm{n}=12)\end{array} \\
F\end{array}$} & \multicolumn{3}{|c|}{$\begin{array}{l}\text { Filhos } \\
(n=71)\end{array}$} \\
\hline & $F$ & $\%$ & $F$ & $\%$ & & & $\%$ & $F$ & $\%$ \\
\hline Família & 12 & 48 & 52,6 & 70,4 & $1^{\circ}$ & 19 & 76 & 63 & 66,3 \\
\hline Parentes/Vizinhos & 0 & & 20 & 21 & & 4 & 16 & 23 & 24,2 \\
\hline e Amigos & & & & & $2^{\circ}$ & & & & \\
\hline Grupo de & 12 & 48 & 23 & 24,2 & & 1 & 8,3 & 9 & 9,4 \\
\hline Trabalho Coleta & & & & & & & & & \\
\hline de Açaí & & & & & $3^{\circ}$ & & & & \\
\hline Associação & 1 & 8,3 & 2 & 2 & & 1 & 8,3 & 0 & \\
\hline Comunitária & & & & & $4^{\circ}$ & & & & \\
\hline Outros Locais & 0 & & 0 & & $5^{\circ}$ & 0 & & 0 & \\
\hline Total de citação & 25 & & 95 & & & 25 & & 95 & \\
\hline
\end{tabular}


Tabela 3. Frequência e Médias dos Contatos Satisfatórios e Insatisfatórios por Campo

\begin{tabular}{|c|c|c|c|c|}
\hline \multirow{3}{*}{ Campos } & \multirow{2}{*}{$\begin{array}{c}\text { Contato } \\
\text { Satisfatório }\end{array}$} & \multicolumn{3}{|c|}{ Contato } \\
\hline & & & Insatisfatório & \\
\hline & $F$ & $\mathbf{M}$ & $F$ & M \\
\hline Família & 55 & 4,58 & 10 & 0,83 \\
\hline Parentes/ & 250 & 20,83 & 15 & 1,25 \\
\hline \multicolumn{5}{|l|}{ Vizinhos/ Amigos } \\
\hline Grupo de Trabalho & 47 & 3,91 & 6 & 0,5 \\
\hline \multicolumn{5}{|l|}{ Coleta de Açaí } \\
\hline Associação & 72 & 6 & 16 & 1,33 \\
\hline \multicolumn{5}{|l|}{ Comunitária } \\
\hline Outros locais & 71 & 5,91 & 5 & 0,41 \\
\hline Mapa & 497 & 41,41 & 52 & 4,33 \\
\hline
\end{tabular}

\section{A) Contatos satisfatórios e insatisfatórios}

No que se refere à funcionalidade, ou seja, à qualidade das relações estabelecidas na rede de apoio social das participantes, foram mencionados 497 classificados como satisfatórios e 52 como insatisfatórios dentre os 549 contatos citados. A tabela 3 mostra uma diferença significativa entre as médias de contatos satisfatórios e insatisfatórios nos campos estudados.

A maior média de contatos satisfatórios está situada no campo de Parentes/ Amigos/Vizinhos (20,83), seguido pela Associação Comunitária (6) e a Família (4,58), Outros Locais $(5,91)$, e, por fim, o Grupo de coleta do Açaí $(3,91)$. Quanto aos contatos insatisfatórios, apresentam uma menor média comparado aos contatos satisfatórios, a média da Associação Comunitária $(1,33)$, seguido pelo Grupo de parentes/Vizinhos/Amigos (1,25), a Família $(0,83)$, no campo do Grupo de Trabalho da coleta do Açaí $(0,5)$, por fim, Outros Locais $(0,41)$.

Os resultados do M5C mostraram o campo Parentes/Vizinhos/ Amigos como o de maior número de con- tatos satisfatórios. Este campo é seguido pela Associação Comunitária, composto particularmente por membros da comunidade e da família. Na sequência, contatos satisfatórios foram mencionados em Outros locais representados pela igreja, escola, faculdade em Belém e Secretaria do Meio Ambiente, e, por fim, a família que apresentou menor número de contatos, pois foram consideradas apenas coabitantes como participantes.

O campo do Grupo de coleta do Açaí apresentou um pequeno número de contatos satisfatórios, é possível que esse resultado seja devido à composição deste estar restrita a familiares próximos exercendo a atividade.

Pode-se identificar a relação de parceria entre os membros da família no trabalho da coleta do açaí. Apesar de haver uma divisão das tarefas por membros e de ocorrer eventuais conflitos, o cuidado e o manejo com o produto, o cuidado com a sua aparência e o rendimento ocorrem de forma conjunta, bem como a divisão dos rendimentos, ficando uma parte para os filhos, e o restante para a manutenção da casa. Observe-se na fala de Célia: 
"O nosso trabalho é em conjunto, os filhos ajudam e recebem o dele. Às vezes sai uma discussão, o meu marido implica, quer as coisas do jeito dele, mas a gente gosto do trabalho, a gente capricha na aparência, para tudo ficar certinho. Eu acho importante o nosso trabalho, porque é do açaí que a gente vende pra conseguir alimento, é o nosso ganha pão, é dele que a gente tira o nosso sustento". (Célia, setembro/2011, Ilha Grande/ São José).

\section{B) Conflitos e Rompimentos}

Quanto aos conflitos, observou-se uma maior frequência nos campos de Parentes/Vizinhos/Amigos e na Família, conforme a Tabela 6. No que tange aos rompimentos, constatou-se um maior número nos campos dos Parentes/ Vizinhos/ Amigos (Tabela 4).
No campo Família, os conflitos são descritos como brigas cotidianas, e um exemplo é o conflito descrito com os filhos: "Ele não tem muito juízo, se envolveu com gente que não presta" (Ruth, novembro/2011, Ilha Combu/ Santo Antônio). No entanto, os filhos permanecem na sua maioria no nível 1 da circunferência, caracterizando um alto grau de proximidade no convívio da família.

A análise das relações mais distantes (níveis 3 e 4 da circunferência) das participantes indica alguns contatos marcados por conflitos, apesar de que, em outros campos, as participantes às vezes indicaram a mesma pessoa em campos diferentes, classificando-as nos níveis 1 e 2 da circunferência. As vivências e as atividades desenvolvidas nas relações nos diferentes contextos pode ser a razão pela qual a mesma pessoa é classificada como conflituosa em um campo e em outro sem conflitos, o que é justificado pela participante Clarice:

Tabela 4. Frequência dos conflitos e rompimentos. Média de proximidade.

\section{$\begin{array}{llll}\text { Campos Conflito } & \text { Rompimento } & \text { Proximidade }\end{array}$}

\begin{tabular}{lccccc} 
& $\boldsymbol{F}$ & $\mathbf{M}$ & $\boldsymbol{F}$ & $\mathbf{M}$ & $\boldsymbol{M}$ \\
\hline Família & 12 & 1 & 0 & 0 & 0,028 \\
Parentes/ & 15 & 1,25 & 2 & 0,16 & 0,082 \\
Vizinhos/ & & & & &
\end{tabular}

Amigos

$\begin{array}{llllll}\text { Grupo de } & 6 & 0,5 & 0 & 0 & 0,020\end{array}$

trabalho

Coleta de

Açaí

$\begin{array}{llllll}\text { Associação } & 11 & 0,91 & 2 & 0,16 & 0,030\end{array}$

Comunitária

$\begin{array}{llllll}\text { Outros } & 4 & 0,33 & 2 & 0,16 & 0,023\end{array}$

locais

Mapa 
"Aqui em casa a gente se dá bem, ele é um bom marido, já melhorou muito. Mas lá no açaizeiro às vezes ele é muito implicante, e olha que eu sou esperta, mas ele quer tudo do jeito dele". (Clarice, Maria das Dores, novembro/2011. Ilha do Combu/Santo Antônio).

Por outro lado, os conflitos podem ocorrer pela valorização da privacidade e da autonomia, acarretando dificuldades de convivência ou rompimento da relação, é assim que Vanda caracteriza a relação com o seu sogro:

"Tem muito conflito com o meu sogro. Ele se mete muita na nossa vida. Mas por outro lado, os pais dele ajudam muito, mas agora eu estou evitando ir lá e deixar as crianças. A mentalidade deles que é muito atrasada. Mas por eles eu ficava aqui em casa esperando nem sei lá o que, ficava ali com as meninas. Pra eles eu deveria ser uma Amélia." (Vanda, dezembro/2011, Ilha do Combu/ Santo Antônio).

No quinto nível da circunferência, as relações se caracterizam como conflituosas com rompimentos, mas que, em alguns momentos, as pessoas convivem em relações formais, como é justificada:

"Tenho briga com a coordenadora da escola. Eu falo com ela, mas me afastei. Ela me atrapalhou muito no meu trabalho no barco". (Vânia, agosto/2011. Ilha Combu/ Santo Antônio).

Como pôde ser observado e descrito no diário de campo, as participantes da pesquisa convivem com os parentes que, na sua maioria, moram nas comunidades ou em proximidades. Apesar da boa convivência com os familiares, muito apoio e ajuda mútua, existem conflitos e rompimentos que estão relacionados, na maioria das vezes, aos momentos no cotidiano das famílias, no trabalho da coleta do açaí e às falhas na organização das associações comunitárias. No entanto, as famílias estão sempre em contato, por serem comunidades pequenas e todos se conhecerem. O maior contato ocorre no cotidiano das famílias e no trabalho do açaí, como declara Célia:

"No açaizeiro cada um faz o seu serviço. Mas sempre tem alguma coisa que dá briga. Mas aí no fim dá certo, porque já se sabe o que vai fazer e é preciso do trabalho, é daqui que sobrevivemos". (Célia, setembro/2011. Ilha Grande/São José).

\section{Discussão}

A rede de relações de apoio presente nas comunidades funciona como um fator importante para que as mulheres consigam exercer a dupla jornada de trabalho, conciliando as tarefas domésticas e o trabalho remunerado, além de garantir a sua participação em atividades da associação comunitária, para isto, elas contam com a ajuda de parentes, vizinhos e amigos. Todas essas modificações nas estruturas familiares e nas relações de gênero, que são associadas a alterações sociais e econômicas, impulsionadas especialmente pelas mulheres que passaram a ingressar no mercado de trabalho e avançar nos níveis educacionais, assumindo muitas vezes a responsabilidade sobre a subsistência da família (Aizpurúa, Jablonski \& Féres-Carneiro (2007).

As mulheres participantes da pesquisa, apesar de considerarem o homem o chefe da casa, acreditam que a participação das mulheres nas decisões familiares é ativa e pode ser maior quando a mulher tem um trabalho remunerado e contribui com o orçamento familiar. A participação no orçamento as torna mais valorizadas e com maior poder de decisão. A participação das mulheres como papel de coadjuvante neste cenário, também é discutido por Silva \& Rocha (2010), do cuidar da casa, dos filhos e do roçadinho ao redor da casa. A mulher, na contemporaneidade, pela sua inserção em diversos espaços sociais, vem apresentando um papel fundamental na sustentabilidade da propriedade, porém esta ainda parece não ter o reconhecimento de seu trabalho na medida em que as suas atividades produtivas são visualizadas como - "não trabalho", uma atividade que não gera renda e recursos para o processo produtivo da agricultura familiar.

Contudo, como pode ser verificado a partir do dado de concepção do trabalho e divisão de papéis, discutido por Silva \& Rocha (2010), o trabalho na coleta do açaí, não garante as mulheres uma mudança de valores, símbolos e ideias referentes ao papel que representam na família. Elas sempre tentam conciliar a nova atividade ao trabalho doméstico e ao cuidado com os filhos, apresentando uma nítida representação da divisão do trabalho - designação prioritária dos homens à esfera produtiva e das mulheres à esfera reprodutiva, assim como, ao mesmo tempo, a captação pelos homens das funções com forte valor social agregado. Neste estudo, consideram que o trabalho mais apropriado das mulheres é no cuidado da casa e dos filhos, e dos homens no trabalho da coleta do açaí e sua comercialização, além de participarem de atividades que elas próprias caracterizam como mais apropriadas para mulheres quando exercem a atividade no açaizeiro. 
Realidade semelhante embora em diferentes contextos de agricultura familiar foi relatada por Almeida, Noronha, Brito, Farias e Andrade (2014). As mulheres são responsáveis pelas atividades domésticas e estão inseridas em outros mercados de trabalho. Além disso, no desempenho de atividades produtivas, nas quais podem mesmo substituir os homens, não é acompanhado do reconhecimento deste como um domínio seu, o que é expresso na noção de "ajuda" que o designa. Além disso, os dados apontam a mulher como a responsável pelo controle do orçamento da família, sendo então a principal gestora do núcleo familiar. Mesmo com pouca renda, elas são capazes de garantir o controle e as metas dos projetos familiares. O que se pode verificar é a capacidade da mulher de enfrentar os problemas cotidianos e em decorrência das próprias experiências em sua tarefa proporcionam uma nova perspectiva aos membros familiares (Simões \& Hashimoto, 2012).

Os resultados deste estudo são discutidos de forma a integrar os dados do MCC (Samuelsson, Thernlund \& Ringstrom, 1996, adaptado por Hoppe, 1998), da entrevista semiestruturada, do DC e da literatura, enfatizando os campos Grupo de Trabalho da coleta do açaí, Parentes/ Vizinhos/Amigos, Família e Associação comunitária. Esses contextos destacaram-se na análise dos resultados por corresponderem tanto aos campos com o maior número de pessoas quanto aos campos que apresentam contatos mais próximos e com qualidade, além de principais fornecedores de apoio.

Especificamente, os campos Parentes/Vizinhos/ Amigos e Família destacam-se por apresentar um maior número de pessoas e de vínculos mais próximos e de maior qualidade. De fato, demonstra que em comunidades isoladas, como as que são apresentadas nas comunidades das ilhas da Belém Insular, é muito provável quase todos guardarem entre si laços de parentesco e fortes laços de amizade e cooperação. $\mathrm{O}$ isolamento e os laços estreitos destas famílias podem ser justificados pela presença do rio, pois este, ao mesmo tempo, que cria vínculos e isolamentos entre as pessoas dessas populações, pode haver maior frequência de interação entre os membros familiares. Criam-se, assim, trajetórias de desenvolvimento tipicamente adaptadas a este modo de vida (Mendes, Pontes, Silva, Bucher-Maluschke, Reis \& Silva, 2008).

Sendo assim, como uma forma de estratégia de sobrevivência, o grande número de contatos com grande proximidade das famílias, grupos de parentes, vizinhos e amigos constituem a principal fonte de apoio social para as mulheres dessas comunidades. Esses resultados estão em acordo com as ideias de Machado (2014) que ao considerar o crescimento da competição e das dificuldades impostas pelo mercado de trabalho, as mulheres deparam-se com inúmeras exigências e dificuldades em realizar o trabalho doméstico, cuidado e na educação dos filhos, gerando a necessidade de uma ampla rede de apoio social.

Os dados apresentam, ainda, o maior número de contatos no grupo de Parentes/Vizinhos/Amigos, o que demonstra ser uma atividade importante para a agregação de apoio social e afetivo das famílias estudadas. É evidente que para essas mulheres o grupo de Parentes/ Vizinhos/Amigos funciona como fonte de novas relações, ampliando as suas redes de apoio. Destaca-se também o fato de que nesse grupo há o maior número de contatos satisfatórios. Nesta perspectiva Sarti (2007) também discute esse efeito protetor que o apoio social oferece está relacionado ao desenvolvimento da capacidade de enfrentamento das adversidades. É o que se observa na realidade das comunidades estudadas, na promoção dos processos de resiliência e desenvolvimento adaptativo das mulheres ribeirinhas. Todas as relações que elas estabelecem com as pessoas dos contextos que participam, advindas dos diversos microssistemas nos quais transita, como família, parentes, amigos e vizinhos, associação comunitária, e grupo de trabalho do açaí, entre outros, podem assumir o papel de fornecer apoio.

Os resultados demonstram que, para a manutenção dessas redes de apoio, as participantes mantêm vínculos nos vários campos e estão classificados em vários níveis de proximidade. Em relação à qualidade dos vínculos, ou seja, à colocação das pessoas nos círculos adjacentes ao centro mostra que as mulheres participantes da pesquisa se concentram, na sua maioria, no primeiro e segundo níveis, demonstrando que as relações mantidas são de grande proximidade, relações de trocas e as retribuições subsequentes. Esse aspecto pode ter como efeito que, com a existência desse estreitamento das relações com a família, rede de vizinhança, parentes e a associação comunitária, as mulheres das comunidades possam participar mais ativamente da vida familiar cotidiana. De modo semelhante, Almeida (2011) e (Costa e Marra, 2013) discutem o papel articulador das mulheres na manutenção de relações com vizinhos e parentes para driblar as condições de vulnerabilidade social, as mulheres tendem a tecer redes de solidariedade.

Dessa forma, as redes de apoio, criadas para uma melhor articulação no desenvolvimento do trabalho nessas comunidades devem ser pensadas como fenômenos importantes para as inter-relações dos vários contextos 
em que as mulheres participantes das pesquisas estão inseridas. Esse resultado demonstra, mais uma vez, a qualidade da relação das mulheres com os parentes e a amplitude do mesossistema que frequentam, à medida que a possibilidade de ajuda atinge o nível da família. As mulheres que desenvolvem o trabalho fora do âmbito familiar buscam ajuda fora desse microssistema, procuram, principalmente, Parentes/Vizinhos/Amigos e a família que compõem também o grupo de trabalho da coleta do açaí que representam figuras de apoio, que estão organizados por meio de instituições, como a vinculação das comunidades a associações comunitárias (mesossistema). Esses dados salientam a importância da disponibilização de recursos e serviços para se configurar realmente como uma rede de apoio, para que essas famílias tenham a possibilidade de desenvolver atividades geradoras de rendimento para a sobrevivência da família.

Assim, o modelo bioecológico proposto por Bronfenbrenner (1996) pode explicar como as interações de que as mulheres dessas comunidades participam e os contextos em que elas estão inseridas constituem uma forma mais complexa em que as relações são estabelecidas entre o organismo humano biopsicológico e as pessoas, objetos e símbolos em seu ambiente imediato e o tempo de forma simultânea. Os contextos, como a comunidade composta pelos Parentes/Vizinhos/Amigos e a família, assim como o Grupo de Trabalho da coleta do açaí, interferem-se mutuamente e afetam conjuntamente o desenvolvimento dessas famílias. Ou seja, as relações e as atividades desenvolvidas nesses contextos criam perspectivas da realização de um trabalho produtivo, valorizando os produtos das comunidades e passam a almejar projetos futuros, como a consolidação da Associação Comunitária, que pode trazer possibilidades de realização de projetos que beneficiem toda a comunidade.

Por outro lado, os dados demonstram também a existência, mesmo que menor, de qualidade dos vínculos nos níveis de proximidade: o terceiro e quarto níveis correspondem às relações mais distantes, e o último nível (periférico) representa os contatos insatisfatórios e com rompimento. Os conflitos se concentram onde também tem mais intensidade de contatos, ou seja, onde a rede é mais intensa, no campo de Parentes/vizinhos/amigos e no campo Família, o que pode ser explicado pela intensidade das redes de apoio, pois isso pode gerar conflitos e insatisfações. Esses dados estão em consonância com as considerações de Carmo (2007) que ter conflitos e tensões provocados pelo aumento da pressão e uma desorganização dentro deste contexto da família.
Os conflitos podem estar relacionados à alta proximidade e intimidade que esses grupos familiares e da comunidade mantêm entre si. Além disso, pode-se descrever que as insatisfações e os conflitos relatados nas redes das mulheres estudadas, as relações com vizinhos, parentes e amigos e familiares das comunidades apresentam uma conotação mais livre e emocional, pois são contatos familiares próximos.

Outro aspecto que deve ser levado em conta é que apesar de a rede de relações com vizinhos e parentes ser importante na vida das famílias, essas possuem multiplicidade de configurações, formas de convivência - diretamente relacionadas a suas condições sociais, crenças e hábitos culturais - e por constituírem espaço de contradições e conflitos, tais famílias apresentam significativas diferenças entre si, mesmo fazendo parte de um mesmo segmento social (Gueiros, 2010). No entanto, a família, bem como os membros das comunidades estudadas, forma um grupo de convivência e uma unidade de cooperação econômica e de consumo material e simbólico, mantida para enfrentar as dificuldades impostas pelo cotidiano e para alcançar determinados objetivos no futuro.

\section{Considerações finais}

A análise dos dados permitiu constatar a importância da rede de apoio social das mulheres investigadas para o desenvolvimento da atividade da coleta do açaí, criando eixos de inserção dessas mulheres em vários contextos e níveis de relacionamento. Os Parentes/Vizinhos/Amigos e a Associação comunitária foram mencionados por essas mulheres de forma a caracterizar uma intensa rede de apoio social. Todas essas ações permitem que essas mulheres circularem por vários contextos, bem como a interação entre as pessoas de outros microssistemas de modo adaptado e com equilíbrio nas relações de poder e proporcionando terem sucesso na execução das atividades e das ações da associação comunitária. Essas experiências implicam transformações não só no âmbito doméstico, mas também criam condições para a presença feminina nos movimentos sociais, estabelecendo, assim, a integração do cenário público com o privado, o que contribui para processos de transformações macrossociais.

Contudo, apesar de a comunidade se beneficiar das intervenções de várias instituições, a inserção de vários projetos de desenvolvimento comunitário e de conhecimentos e difusões de novas tecnologias, tais famílias ainda permanecem em um contexto de empobrecimento econômico local e em vulnerabilidade social. 
A despeito da limitação na quantidade de participantes, para fins de ter uma melhor perspectiva das mulheres ribeirinhas da Amazônia, trabalhos futuros poderiam comparar as redes e percepções das mulheres de outras Ilhas mais isoladas e afastadas do centro urbano. Aconselha-se também investigar outros arranjos de sobrevivência familiar.

Entende-se, por fim, que esse trabalho pode ser útil para a compreensão dos efeitos de políticas públicas, pois foi possível pensar as relações entre as redes de apoio social e a participação das mulheres e suas lideranças nas atividades envolvidas, que explorem os diversos aspectos desses relacionamentos. Essas análises poderiam contribuir para maior compreensão da participação das mulheres na formação da rede de apoio, apontando para uma proposta com bases democráticas e sustentáveis do desenvolvimento das ações comunitárias e no trabalho da coleta do açaí.

\section{Referências}

Almeida, F. A. S. (2011). Monoparentalidade e resiliência: um estudo com mulheres chefes de família em situação de baixa renda. In. Anais do $16^{\circ}$ Encontro Nacional da Associação Brasileira de Psicologia Social (ABRAPSO), Recife, PE.

Almeida, J. A. T., Noronha, C. R. B., Brito, E. R. P., Farias, A. R. B. \& Andrade, H. M. L. S. (2014). A invisibilidade parcial do trabalho feminino no campo das atividades produtivas. In. $18^{a}$ REDOR. UFPE.

Aizpurúa, R. I.; Jablonski, B. \& Féres-Carneiro, T. (2007). Famílias brasileras y argentinas: entre la tradición y la modernidad. Revista Interamericana de Psicología, v. 41, n. 2, p. 189-196.

Ávila, B. (2007). Notas sobre o trabalho doméstico. In: Lima. M.E.B. et. al. (Orgs.). Transformando as relações trabalho e cidadania, produção, reprodução $e$ sexualidade. São Paulo: CUT.

Bronfenbrenner, U. (1996). A ecologia do desenvolvimento: experimentos naturais e planejados. Porto Alegre: Artmed.

Carneiro, E. F., Fraxe, T. J. P., Mourão, R. R. \& Rivas, A. A. F. (2007). Estratégias de comercialização dos agricultores familiares em comunidades ribeirinhas. In: Fraxe, T. de J. P., Pereira, H. dos S. \& Witkoski, A. C. Comunidades ribeirinhas amazônicas: modos de vida e uso dos recursos naturais.(pp 199-215) Manaus: EDUA.

Carmo, M. (2007). Configurações familiares: um novo paradigma. Revista da Abordagem Gestáltica, 13(2), 260-262.

Costa, F. Á. de O. \& Marra, M. M. (2013). Famílias brasileiras chefiadas por mulheres pobres e monoparentalidade feminina: Risco e proteção. Revista Brasileira de Psicodrama. 144-153.
Cruz. V. C. (2008). O rio como espaço de referencia identitária: Reflexões sobre a identidade ribeirinha na Amazônia. In: Trindade, S. \& Tavares, M. G. C. Cidades Ribeirinhas na Amazônia: Mudanças e Permanências. Ed. Universitária UFPA.

Gueiros, D. A. (2010). Família e trabalho social: intervenções no âmbito do Serviço Social. Rev. Katál. Florianópolis v. 13 n. 1 p. 126-132.

Hoppe, M. (1998). Redes de apoio social e afetivo de crianças em situação de risco. Dissertação de Mestrado não publicada. Curso de Pós-Graduação em Psicologia do Desenvolvimento, Universidade Federal do Rio Grande do Sul. Porto Alegre, RS.

Lomba. R. M. \& Nobre-Junior, B. B. (2013). A relação rural-urbano a partir das cidades ribeirinhas: o papel do comércio popular (feiras) na cidade de Afuá (PA). Belém. Revue Franco Brésilienne de Geographie (Confins).

Machado, M. S. (2014). Trabalho remunerado e trabalho doméstico: conciliação? In: Ávila, M. B. \& Ferreira, V. (org.). Trabalho remunerado e trabalho doméstico no cotidiano das mulheres. (pp 51-76). Recife. SOS Corpo.

Mendes, L. S. A., Pontes, F. A. R., Silva, S. S. C., Bucher-Maluschke, J. S. N. F., Reis, D. C. \& Silva, S. D. B. (2008). Inserção Ecológica no Contexto de uma Comunidade Ribeirinha Amazônica. Revista Interamericana de Psicologíal Interamerican Journal of Psychology, 42 (1), 1-10.

Montali, L. (2014). Mudanças na familia, no mercado de trabalho e nos arranjos familiares. Friedrich-Ebert-Stiftung (FES). São Paulo.

Pinto, M. A., Afonso, T. Pontes, F. A. R. \& Silva, S. S. da C. (2016). O Cotidiano de famílias de uma Comunidade Ribeirina da Ilha do Combu, Belém/ PA. In. Colegare, M. G. A. \& Higuchi, M. I. G. Nos Interiores da Amazonia: leituras psicossociais. (Vol. 1, pp. 173-192). Editora Curitiba, PR: CRV.

Pinto, M. A., Pontes, F. A. R. \& Silva, S. S. da C. (2013). A Rede de Apoio Social e o Papel da Mulher na Geração de Ocupação e Renda no Meio Rural. Rev. Temas em Psicologia. Vol. 21, n 2, 297-315.

Samuelsson, M., Thernlund, G., \& Ringstrom, J. (1996). Using the five maps to describe the social network of children: A methodological study. International Journal Behavioral Development, 19, p. 327-45.

Sarti, C. A. (2007). A família como espelho: um estudo sobre a moral dos pobres. 4. ed. São Paulo: Cortez.

Simonian, L. T. L. (2007). Tendências recentes quanto à sustentabilidade no uso dos recursos naturais pelas populações tradicionais amazônicas. In: Aragón, E. (Org.). Populações e meio ambiente no Pan-Amazônia. (p. 25-44). Belém: NAEA.

Silva S. H. da \& Rocha, S. D. da, (2010). A divisão sexual do trabalho na agricultura na amazônia: O "não trabalho feminino". Revista eletrônica Mutações/ BELÉM. Julho-janeiro. p. 1-15.

Siqueira, A. C., Betts, M. K. \& Del' Aglio, D. D. (2006). A Rede de Apoio Social e Afetivo de Adolescentes. Institucionalizados no Sul do Brasil. Revista Interamericana de Psicología/Interamerican Journal of Psychology, (2), p. 149-158.

Simões, F. I. W. \& Hashimoto, F. (2012). Mulher, mercado de trabalho e as configurações familiares do século XX. Revista Vozes dos Vales: Publicações Acadêmicas Reg.: 120.2.095-2011 - UFVJM.

Vaux, A. (1988): Social Support: Theory, Research, and Intervention. New York: Praeger.

Submetido em: 15-5-2017

Aceito em: 20-3-2018 